Eur. J. Clin. Chem. Clin. Biochem.

Vol. 29, 1991, pp. 795-800

(C) 1991 Walter de Gruyter \& Co.

Berlin - New York

\title{
Assessment of a Selected Method for Creatinine with Special Emphasis on Bilirubin Interference
}

\author{
By L. Zwang and B. G. Blijenberg \\ Department of Clinical Chemistry, Academic Hospital Rotterdam-Dijkzigt, The Netherlands
}

(Received April 3/August 30, 1991)

Summary: An HPLC-based method for the determination of creatinine was evaluated, with emphasis on interference by bilirubin.

The method differed from other procedures, in that deproteinization was by ultrafiltration instead of precipitation with trichloroacetic acid. This allows a rapid, direct analysis by HPLC with very few experimental steps.

Analytical results showed linearity up to $5000 \mu \mathrm{mol} / 1$ and an average analytical recovery of $100 \%$.

Within-day imprecision was $0.8-1.4 \%$, and day-to-day imprecision was $0.5-2.4 \%$.

\section{Introduction}

It has been known for years that the routine determination of creatinine in serum can present laboratory workers with serious problems.

The traditionally used methods are all based on the well known Jaffé reaction (1). In spite of the many modifications of this method, interference by one or more substances still exists. A comprehensive list is given by Young et al. (2).

We met this problem in our laboratory after the introduction of the Technicon Chem 1 analyser. Clinicians criticized the value of some creatinine results, and mosst of the specimens in question turned out to be icteric. Bilirubin, the most troublesome interferent in the creatinine determination, is elevated $(>20$ $\mu \mathrm{mol} / \mathrm{l})$ in about $16 \%$ of our daily workload. It therefore appeared expedient to study the state of the art of the Chem 1 analyser with respect to interference by bilirubin with the creatinine determination. We have already drawn attention to this interference in a previous publication (3).
It was clear that in order to answer this question a reliable method was needed. From the literature it is known that high-performance liquid chromatography (HPLC) can be suitable analytical method.

High-performance liquid chromatography for the determination of creatinine in serum has been described, using both reversed-phase $(5-8)$ and ion exchange systems (9-12).

However, almost all techniques described have a low throughput, either due to long column preconditioning or to gradient elution.

Furthermore the use of trichloroacetic acid, used in a number of techniques as a deproteinizing agent, is not free of risks. The risks are inclusion of creatinine and conversion of creatine to creatinine (4).

We therefore considered ultrafiltration as an independent means of deproteinization (13). Deproteinization of serum by ultrafiltration and subsequent direct analysis of the aqueous supernatant could offer a true advantage over the established methods that use trichloroacetic acid. 


\section{Materials and Methods}

\section{Materials}

\section{Reagents}

All chemicals were at least reagent grade. Creatinine (>99\%) bilirubin, trichloroacetic acid $(20 \%)$, acetic acid $(100 \%)$, hydrochloric acid (37\%), dimethylsulphoxide, sodium carbonate, methanol Lichrosolv and acetic acid, were obtained from Merck, Darmstadt, Germany. The concentration of trichloroacetic acid used was $0.6 \mathrm{~mol} / \mathrm{l}(10 \%)$.

Lithium acetate dihydrate, MicroSelect, was obtained from Fluka BioChemika AG Buchs, Switzerland.

Creatinine iminohydrolase (EC 3.5.4.21) used for interference studies was obtained from Sigma, St Louis, MO, U. S. A.

Water was purified with the Milli-Q water system from Millipore, Molsheim, France.

A stock solution of $10 \mathrm{mmol} / \mathrm{l}$ creatinine was prepared in 20 $\mathrm{mmol} / \mathrm{l}$ hydrochloric acid and was used to make seven aqueous standard solutions covering the range $50-1000 \mu \mathrm{mol} / 1$.

The serum samples were stored for up to one month at $-80^{\circ} \mathrm{C}$ until further use.

Standard reference material 909 from the National Institute of Standards and Technology, U.S. A. was used together with two levels (Kontrollogen-L and -LP) control sera from Behringwerke A.G., Marburg, Germany, to evaluate the HPLC method.

Furthermore, six reference sera (A, B, C, D, E, F) from the Deutsche Gesellschaft für Klinische Chemia, Zentrale Referenzinstitution were used as control material. In all sera the creatinine determination was performed by isotope dilution-mass spectrometry and by a validated reference method.

\section{Methods \\ Ultrafiltration}

The disposable Centrifree Micropartition System from Amicon used in a fixed-angle rotor (JA-21 Beckman) provides an ultrafiltrate which is almost free from protein after centrifugation at $1000 \mathrm{~g}$.

In the removal of protein from a serum sample by ultrafiltration, there is a decrease of the total sample volume due to the removal of proteins.

A factor of 0.9456 is used to adjust for this change in volume according to Weast (15).

\section{Sample preparation}

A serum sample $(100-300 \mu l)$ was centrifuged for 20 minutes and $10 \mu \mathrm{l}$ ultrafiltrate was directly injected into the HPLC system.

\section{Blank sample preparation}

Serum $(500 \mu \mathrm{l})$ was mixed with $50 \mu \mathrm{l}$ Tris buffer containing 20 $\mathrm{kU} / \mathrm{l}$ creatinine iminohydrolase and incubated in a closed tube for 60 minutes at $37^{\circ} \mathrm{C}$.

\section{Bilirubin interference}

The protocol worked out by the Sociéte Française de Biologie . Clinique was used to study interference by bilirubin (14).

\section{High performance liquid chromatography (HPLC)}

The HPLC system from Spectra Physics consisted of a SP8800 HPLC pump, a SP8780 autosampler, a SP8790 column heater, a SP8450 UV detector and a SP4290 integrator. The HPLC procedure is essentially according to Kagedal \& Olsson (11).

The weak cation-exchange column was a $150 \times 4.6 \mathrm{~mm} \mathrm{I.D}$. column from Bio-Rad, Richmond, CA, U.S.A., urinary metanephrine kit, Cat. No. 195-6001.

The elution buffer was lithium acetate $15 \mathrm{mmol} / \mathrm{l}$. The $\mathrm{pH}$ was adjusted to 4.80 with acetic acid and filtered $(0.45 \mu \mathrm{m}$ cellulose acetate/nitrate membrane, Millipore, Molsheim, France) before use. The eluent was a mixture of lithium acetate - methanol $(95+5$ by vol.), and the flow rate was $1.0 \mathrm{ml} / \mathrm{min}$.

Because there was no dilution of the sample with trichloroacetic acid as in the original procedure, we preferred to reduce the injection volume from 20 to $10 \mu \mathrm{l}$ in order to minimize peak broadening. The column temperature was raised to $40^{\circ} \mathrm{C}$, in order to diminish peak tailing. The absorbance was monitored at $234 \mathrm{~nm}$, and calibration was performed with aqueous external standards.

\section{Results}

Preliminary experiments, performed exactly according to the procedure of Kagedal \& Olssen with aqueous standard material, occasionally showed a second peak or tailing peaks. We suspected trichloroacetic acid, because reduction of the amount of trichloroacetic acid more or less solved this problem. We decided to study this phenomenon at a later stage and to circumvent the problem by applying the Amicon Centrifree Micropartition System, because this system had worked very well in initial experiments. This system provides an almost protein- and bilirubin-free ultrafiltrate and requires only $100 \mu \mathrm{l}$ of serum.

Because of this modification we had to re-examine the precision, accuracy, linearity, sensitivity and recovery of the method.

\section{Precision}

Analytical imprecision was calculated from two commercially available human control sera with creatinine levels of $123.5 \mu \mathrm{mol} / \mathrm{l}$ (Kontrollogen L) and 293 $\mu \mathrm{mol} / 1$ (Kontrollogen LP). Within-day imprecision was determined by six replicate analyses of Kontrollogen $L$ and LP.

Between day imprecision was assessed using the same controls, divided into aliquots and stored at $-20^{\circ} \mathrm{C}$. On 10 separate occasions an aliquot of each level was thawed and analysed. The results are shown in table 1.

\section{Accuracy}

To evaluate the accuracy of the HPLC method, we analysed seven sera, the creatinine values of which had been determined by isotope dilutions-mass spectrometry or by a reference methrod (see tab. 2). 
Tab. 1. Within- and between-day imprecision of creatinine measurements.

\begin{tabular}{llll}
\hline & $\begin{array}{l}\text { Mean } \\
\mu \mathrm{mol} / \mathrm{l})\end{array}$ & $\begin{array}{l}\text { SD } \\
(\mu \mathrm{mol} / \mathrm{l})\end{array}$ & $\begin{array}{l}\text { CV } \\
(\%)\end{array}$ \\
\hline Within-day & 121 & 1.7 & 1.4 \\
$(\mathrm{n}=6)$ & 296 & 2.2 & 0.8 \\
Between-day & 121 & 1.9 & 1.6 \\
$(\mathrm{n}=10)$ & 293 & 3.7 & 1.3 \\
\hline
\end{tabular}

Tab. 2. Accuracy of creatinine measurements by HPLC.

\begin{tabular}{lllllr}
\hline Pool & $\begin{array}{l}\text { Refer- } \\
\text { ence } \\
\text { value } \\
(\mu \mathrm{mol} / \mathrm{l})\end{array}$ & Mean $^{\mathrm{b}}$ & SD & CV & \multicolumn{1}{c}{$\begin{array}{l}\text { Re- } \\
\text { cov- } \\
\text { eryc } \\
(\%)\end{array}$} \\
\hline A & 538 & 544.1 & 12.8 & 2.4 & 101.1 \\
B & 155 & 161.0 & 2.5 & 1.6 & 103.9 \\
C & 221 & 218.2 & 4.1 & 1.9 & 98.7 \\
D & 109 & 110.1 & 2.6 & 2.4 & 101.0 \\
E & 593 & 607.0 & 12.0 & 2.0 & 102.4 \\
F & 120 & 121.1 & 1.2 & 1.0 & 100.9 \\
SRM 909 & 151.3 & 151.2 & 0.8 & 0.5 & 99.9 \\
Kontrollogen L & 123.5 & 120.8 & 0.9 & 0.7 & 97.8 \\
Kontrollogen & 293.0 & 297.9 & 2.9 & 1.0 & 101.6 \\
LP & & & & & \\
\hline
\end{tabular}

a Values determined by the reference method used by the 'Deutsche Gesellschaft für Klinische Chemie', except for S. R. M. 909.

b mean values are calculated from $n=4$ except for Kontrollogen $\mathrm{L}$ and LP, where $\mathrm{n}=10$.

c Percent of the reference value.

For all sera the mean concentration of creatinine measured by HPLC was within $97.8 \%$ to $103.9 \%$ of the stated value.

\section{Linearity}

We used a calibration curve prepared from aqueous creatinine standards covering the range $0-1000$ $\mu \mathrm{mol} / 1$ creatinine. A representative calibration curve is shown in figure 1 . The method proved to be linear up to $5000 \mu \mathrm{mol} / 1$, using an extended calibration set of $1500,2000,3000,5000 \mu \mathrm{mol} / 1$.

\section{Sensitivity}

The sensitivity in terms of the differentiation of a peak from background noise was estimated to be 0.25 $\mu \mathrm{mol} / \mathrm{l}$ (three times the noise).

\section{Recovery}

Recovery of creatinine from the ultrafiltration system was checked by means of three aqueous creatinine

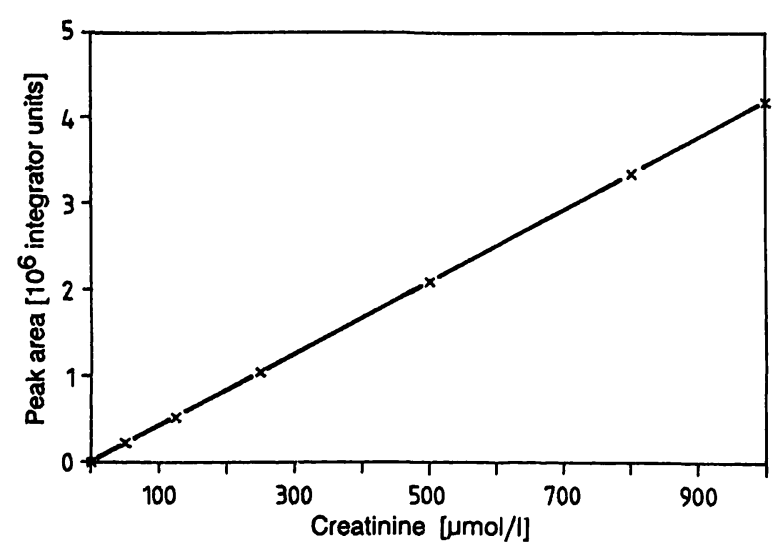

Fig. 1. Calibration curve prepared from aqueous creatinine standards; all points represent the mean of triplicate injections. $y=4398 x+700, S_{x}=0.8, \quad S_{y}=700$, $\mathrm{n}=18, \mathrm{r}^{2}=0.999999$.

standards $(125,500$ and $1000 \mu \mathrm{mol} / \mathrm{l})$. Furthermore we added an aqueous creatinine standard $(100 \mu \mathrm{mol} / \mathrm{l})$ to ten serum samples with different creatinine concentrations and the same standard to ten serum samples with a creatinine level of about $90 \mu \mathrm{mol} / 1$ (see tab. 3).

To be absolutely sure that the ultrafiltrate represents the true creatinine concentration of the sample, we also used the standard-addition technique to estimate the creatinine concentration of the two calibrators, Kontrollogen $\mathrm{L}$ and Kontrollogen LP, and the S. R. M. 909 of the National Institute of Standards and Technology.

Creatinine was added to a serum sample at a concentration of zero, once and twice the estimated creatinine concentration. Four HPLC analyses were performed on each sample.

The average area of these four analyses was used to calculate the linear regression line through these three points. The recovery of the additions was found to be $99.8 \% \pm 0.5 \%$.

The results are shown in table 4.

\section{Interference by bilirubin}

Conjugated and unconjugated bilirubin were investigated separately as possible sources of interference. The conjugated samples were taken from our daily workload, by measuring the total bilirubin level as well as the conjugated fraction with the Technicon Chem-1. The selected samples had a total bilirubin concentration of $>100 \mu \mathrm{mol} / \mathrm{l}$, range $102-564$ $\mu \mathrm{mol} / \mathrm{l}$, mean $210 \mu \mathrm{mol} / \mathrm{l}$, the conjugated fraction being elevated, range $10-279 \mu \mathrm{mol} / \mathrm{l}$, mean 117 $\mu \mathrm{mol} / \mathrm{l}$. 
Tab. 3. Analytical recovery of creatinine after ultrafiltration. a) aqueous standards;

b) 10 serum samples with a creatinine content of approximately $90 \mu \mathrm{mol} / \mathrm{l}$;

c) 10 serum samples with a creatinine content ranging from 65 to $305 \mu \mathrm{mol} / \mathrm{l}$.

\begin{tabular}{|c|c|c|c|}
\hline & \multicolumn{3}{|c|}{ Creatinine } \\
\hline & $\begin{array}{l}\text { added } \\
(\mu \mathrm{mol} / \mathrm{l})\end{array}$ & $\begin{array}{l}\text { found } \\
(\mu \mathrm{mol} / \mathrm{l})\end{array}$ & $\begin{array}{l}\text { recovery } \\
(\%)\end{array}$ \\
\hline \multicolumn{4}{|c|}{ a. Aqueous standards } \\
\hline & 120 & 119.3 & 99.4 \\
\hline & 500 & 497.5 & 99.5 \\
\hline & 1000 & 1000.9 & 100.1 \\
\hline \multicolumn{4}{|c|}{ b. Serum, low creatinine } \\
\hline \multirow[t]{2}{*}{1} & - & 81 & \\
\hline & 100 & 183 & 102 \\
\hline \multirow[t]{2}{*}{2} & - & 89 & \\
\hline & 100 & 188 & 99 \\
\hline \multirow[t]{2}{*}{2} & - & 99 & \\
\hline & 100 & 198 & 99 \\
\hline \multirow[t]{2}{*}{4} & - & 93 & \\
\hline & 100 & 193 & 100 \\
\hline \multirow[t]{2}{*}{5} & - & 85 & \\
\hline & 100 & 185 & 100 \\
\hline \multirow[t]{2}{*}{6} & $1-$ & 83 & \\
\hline & 100 & 185 & 102 \\
\hline \multirow[t]{2}{*}{7} & - & 82 & \\
\hline & 100 & 183 & 101 \\
\hline \multirow[t]{2}{*}{8} & - & 72 & \\
\hline & 100 & 173 & 101 \\
\hline \multirow[t]{2}{*}{9} & $-\overline{0}$ & 75 & \\
\hline & 100 & 175 & 100 \\
\hline 10 & - & 71 & \\
\hline \multicolumn{3}{|l|}{$(\mathrm{n}=10)$} & $\stackrel{99}{\overline{\mathrm{x}}=100.3 \%}$ \\
\hline \multicolumn{4}{|c|}{ c. Serum, high creatinine } \\
\hline \multirow[t]{2}{*}{11} & - & 65 & \\
\hline & 100 & 165 & 100 \\
\hline \multirow[t]{2}{*}{12} & - & 167 & \\
\hline & 100 & 268 & 101 \\
\hline \multirow[t]{2}{*}{13} & $-\overline{0}$ & 342 & \\
\hline & 100 & 442 & 100 \\
\hline \multirow[t]{2}{*}{14} & - & 375 & \\
\hline & 100 & 474 & 99 \\
\hline \multirow[t]{2}{*}{15} & - & 172 & \\
\hline & 100 & 273 & 101 \\
\hline 16 & $\bar{n}$ & 137 & \\
\hline \multirow[t]{2}{*}{17} & $\begin{array}{c}100 \\
-\end{array}$ & $\begin{array}{l}237 \\
249\end{array}$ & 100 \\
\hline & 100 & 349 & 100 \\
\hline \multirow[t]{2}{*}{18} & - & 201 & \\
\hline & 100 & 300 & 99 \\
\hline \multirow[t]{2}{*}{19} & - & 166 & \\
\hline & 100 & 264 & 98 \\
\hline 20 & - & 305 & \\
\hline$(n=10)$ & 100 & 405 & $\begin{array}{l}100 \\
\bar{x}=99.8 \%\end{array}$ \\
\hline
\end{tabular}

\section{Conjugated bilirubin}

We analysed approximately 100 samples with the HPLC method and with the Chem 1 analyser, each sample being analysed twice. First an ultrafiltrate from the native serum was used to measure the creatinine concentration, next an aliquot of the same
Tab. 4. Estimation of the creatinine concentration in triplicate of Kontrollogen L and LP, and S. R. M. 909 with standard addition to eliminate volume changes due to filtration.

\begin{tabular}{lllll}
\hline Pool & $\begin{array}{l}\text { Reference } \\
\text { value }^{\mathrm{a}} \\
(\mu \mathrm{mol} / \mathrm{l})\end{array}$ & $\begin{array}{l}\text { Run 1 } \\
(\mu \mathrm{mol} / \mathrm{l})\end{array}$ & $\begin{array}{l}\text { Run 2 } \\
(\mu \mathrm{mol} / \mathrm{l})\end{array}$ & $\begin{array}{l}\text { Run 3 } \\
(\mu \mathrm{mol} / \mathrm{l})\end{array}$ \\
\hline SRM 909 & 151.3 & 151.1 & 151.6 & 152.4 \\
Kontrollogen L & 123.5 & 120.7 & 120.2 & 118.8 \\
Kontrollogen LP & 293.0 & 298.7 & 299.5 & 292.9 \\
\hline
\end{tabular}

a Values determined by the reference method used by the 'Deutsche Gesellschaft für Klinische Chemie', except for S.R.M. 909.

serum was incubated with creatinine iminohydrolase, and an ultrafiltrate was also analysed with the HPLC.

In none of 100 samples did we find interfering peaks due to bilirubin or other substances. An example is given in figure 2, a serum sample with a total bilirubin concentration of $385 \mu \mathrm{mol} / 1$.
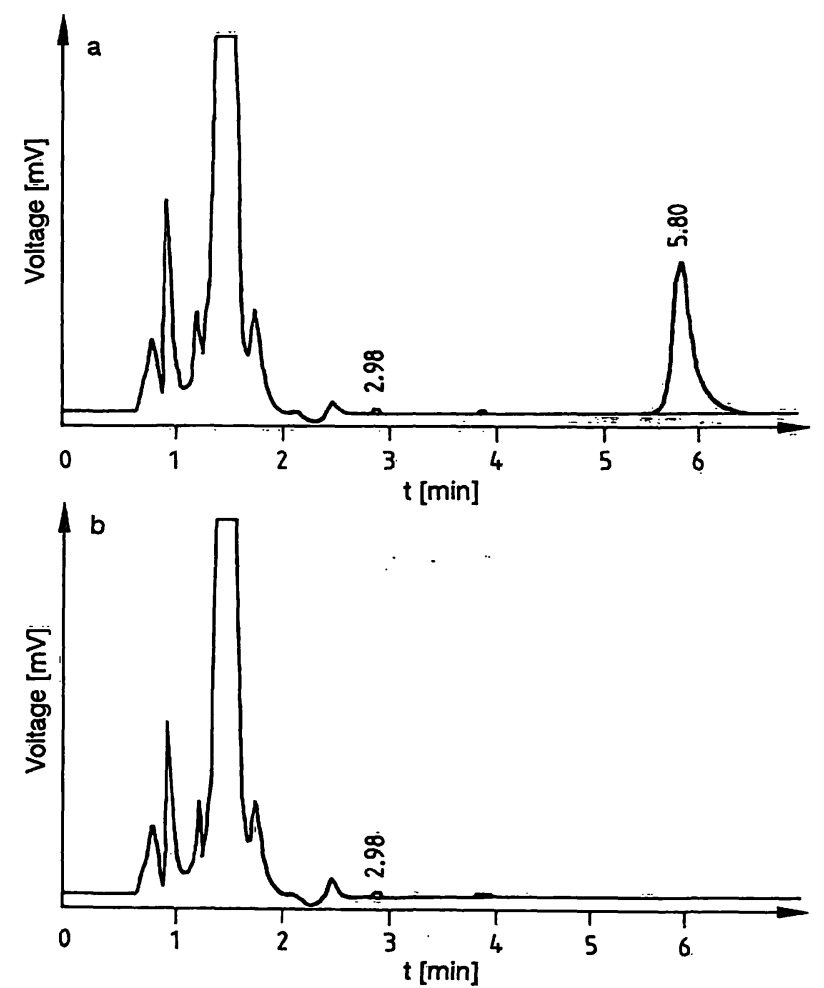

Fig. 2. Chromatogram of a serum sample with an elevated bilirubin concentration of $385 \mu \mathrm{mol} / 1$ and a creatinine concentration of $85 \mu \mathrm{mol} /$ before (a) and after (b) treatment with creatinine iminohydrolase; the peak at 5.80 minutes is creatinine, attenuation is $32\left(2^{5}\right) .1000 \mathrm{mV}=$ full scale

\section{Non-conjugated bilirubin}

We investigated bilirubin added to serum, and added to an albumin/creatinine mixture, according to the CERMAB protocol (14). The creatinine concentrations in serum were 78,179 and $269 \mu \mathrm{mol} / 1$ and in the albumin solution 89,223 and $445 \mu \mathrm{mol} / \mathrm{l}$. The 
bilirubin concentrations $7,30,60,110,250,360,420$ $\mu \mathrm{mol} / 1$ in all dilutions.

The results revealed no interference from unconjugated bilirubin, as shown in figure 3.

Apart from these samples, we studied samples from neonates. These samples $(n=15)$ were incubated with creatinine iminohydrolase. Again we found no interfering peak in any chromatogram.

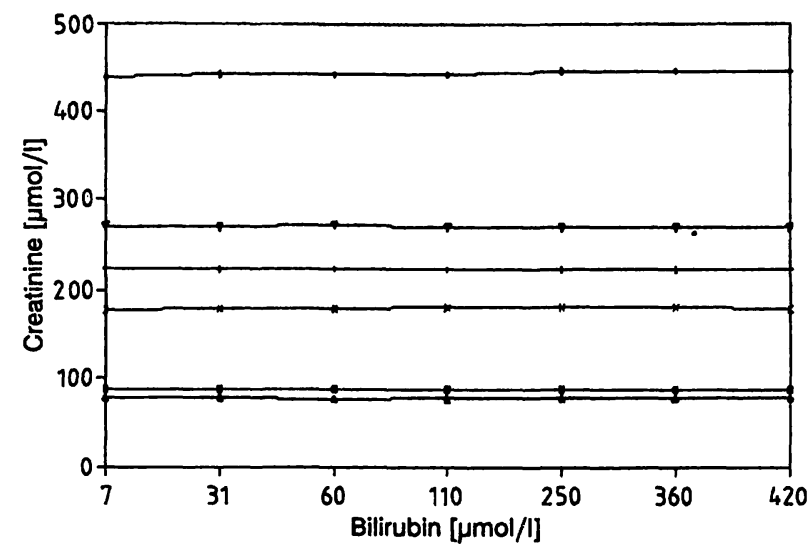

Fig. 3. The interferogram of bilirubin. Serum samples (creatinine $78(\Delta), 179(x)$ and $269(\nabla) \mu \mathrm{mol} / \mathrm{l})$ and albumin samples (creatinine 89 (घ), $223(1)$ and $445(1) \mu \mathrm{mol} / \mathrm{l}$ ) did not show any interference.

\section{Discussion}

In his review of the estimation of creatinine (16) Spencer mentioned the importance of the effect of bilirubin in kinetic Jaffé procedures. Furthermore, he said that HPLC methods are relatively quick for single estimations and that the between-day precision could be compared to most Jaffé procedures.

The weak cation exchange procedure of Kagedal \& Olssen (11), has introduced a new era of creatinine estimations. Interference studies showed no interference by uric acid, caffeine, xanthine and several drugs, but bilirubin was not investigated. Because of the importance of creatinine concentration as a clinical parameter and because of the negative interference of elevated bilirubin concentrations we wondered whether the HPLC procedure could serve as an alternative for our routine method in emergency cases. However, the use of trichloroacetic acid also possibly causes interference, so we circumvented this problem by using an ultrafiltration step. A second advantage of the replacement of trichloroacetic acid by the Amicon ultrafiltration system is the elimination of all dilution steps, and in our opinion this is the reason that our precision and recovery are somewhat better than reported by Kagedal \& Olsson. Accuracy also proved to be good. Retention times for creatinine were reproducible and unaffected by creatinine concentration and injection volume.

Treatment with creatinine iminohydrolase proved that the peak with a retention time of 5.80 minutes was solely due to the presence of creatinine.

Elevated bilirubin levels did not once show interference with any sample after treatment with creatinine iminohydrolase.

Furthermore, co-elution of an interfering substance was not observed in any of the examined "normal" samples used in the initial experiments.

In conclusion, the use of HPLC in combination with a weak cation exchanger to determine creatinine in serum is in our view a very fast, easy to use and accurate back-up system for patient sera with elevated bilirubin levels. In general we feel that our method meets the standard of a candidate reference method. We prefer the use of the standard addition technique instead of applying a protein correlation factor. At the moment we are comparing both modifications, together with a determination of the water content (17).

\section{Acknowledgement}

We would like to thank Dr. G. Röhle (Deutsche Referenzinstitution, Bonn) for kindly providing control sera, Dr. G. Schumann (Medizinische Hochschule, Hannover) for stimulating discussions, Bayer-Technicon Instruments (The Netherlands) for financial support for materials, and Miss $E$. Liesting for her skilfull chemical support.

\section{References}

1. Jaffé, M. Z. (1886) Über den Niederschlag, welchen Pikrinsäure in normalem Harn erzeugt und über eine neue Reaktion des Kreatinins. Z. Physiol. Chem. 10, 391-400.

2. Young, D. S. (1990) Effect on drugs on Clinical Laboratory Tests, A. A. C. C. Press, Washington D. C. 20006.

3. Blijenberg, B. G., Boerma, B. J. M. \& Leijnse, B. (1989) An evaluation of the improved Technicon Chem 1 system. J. Clin. Chem. Clin. Biochem. 27, 457-469.
4. Edgar, G. \& Shiver, H. E. (1925) The equilibrium between creatine and creatinine in aqueous solution. The effect of the hydrogen ion. J. Am. Chem. Soc. 47, 1179.

5. Siekmann, L. (1984) Determination of creatinine in human serum by isotope dilution-mass spectrometry. J. Clin. Chem. Clin. Biochem. 23, 137-144.

6. Schumann, G. \& Büttner, J. (1986) A candiate reference method for creatinine with HPLC. Z. Anal. Chem. 324, $278-279$. 
7. Okuda, T., Oie, T. \& Nishida, M. (1983) Liquid-chromatography measurement of creatinine in serum and urine. Clin. Chem. 29, $851-853$.

8. Spierto, F. W., MacNeil, M. L., Culbreth, P., Duncan, I. \& Burtis, C. A. (1980) Development and validation of a liquid chromatographic procedure for serum creatinine. Clin. Chem. 26, 286-290.

9. Weatherburn, M. W., Trotman, R. B. B. \& Jackson, S. H (1978) Specific method for serum creatinine determination based on ion exchange chromatography and an automated alkaline picrate reaction. A proposed reference method. Clin. Biochem. 4, 159-166.

10. Rosano, G. T., Ambrose, R. T., Wu, A. H. B., Swift, T. W. \& Yadegarl, P. (1990) Candidate reference method for determining creatinine in serum: Method development and interlaboratory validation. Clin. Chem. 36, 1951-1955.

11. Kagedal, B. \& Olsson, B. (1990) Determination of creatinine in serum by high performance liquid chromatography: a comparison of three ion-exchange methods. J. Chromatogr. $527,21-30$.
12. Guy, J. M. \& Legg, E. F. (1990) An improvement cation exchange HPLC method for the measurement of serum creatinine. Ann. Clin. Biochem. 27, 223-226.

13. da Foncesca-Wollheim, F., Heinze, K. G., Lomsky, K. \& Schreiner, H. (1988) Serum ultrafiltration for the elimination of endogenous interfering substances in creatinine determination. J. Clin. Chem. Clin. Biochem. 26, 523-525.

14. Société Française de Biologie Clinique. Cómmission "Validation de Techniques" = Protocbl de validation de techniques (document B, stade 3). (1986) Ann. Biol. Clin. 44, $686-745$.

15. Weast, R. C. (ed.) Handbook of Chemistry and Physics. The Chemical Rubber Co, 18901 Crasewood Parkway, Cleveland, Ohio, 44128 55th edition (1974-1975) D-221.

16. Spencer, K. (1986) Analytical reviews in clinical biochemistry: the estimation of creatinine. Ann. Clin. Biochem. 23, $1-25$.

17. van Kreel, B. K., Wulkan, R. W. \& Leijnse, B. L. (1988) Serum water determination by means of microwave evaporation. J. Clin. Chem. Clin. Biochem. 26, 579-581.

\section{Zwang}

Academic Hospital Rotterdam-Dijkzigt

Department of Clinical Chemistry

Dr. Molewaterplein 40

NL-3015 GD Rotterdam 